\title{
Citar e referenciar: uma estratégia formativa para o uso ético da informação e prevenção do plágio em meio académico
}

\author{
Tatiana Sanches ${ }^{I}$ \\ http://orcid.org/0000-0002-4902-2628 \\ ${ }^{I}$ Universidade de Lisboa, Lisboa, Portugal. \\ Pós-doutorado em Ciência da Informação.
}

http://dx.doi.org/10.1590/1981-5344/3214

Partindo da hipótese de haver maior impacto na prevenção do plágio se for realizada uma intervenção significativa ao longo da formação académica dos alunos, em particular em literacia da informação, pretende-se observar como a formação específica em citações e referências contribui para prevenir o plágio. Apresenta-se um estudo de caso, com enfoque na análise de inquéritos por questionário a alunos do ensino superior. Descreve-se um módulo de formação - Citar e referenciar com a norma APA - considerado estratégico para a prevenção do plágio académico, enquadrado como resposta às necessidades dos utilizadores e apoiado no ensino de competências em literacia da informação, como estratégia para prevenir o plágio. O programa de formação da biblioteca, baseado em standards internacionais para o ensino da literacia da informação, além de se dedicar à instrução sobre técnicas de pesquisa, seleção, avaliação, utilização e apresentação da informação, acrescentou um módulo cujos resultados de avaliação e de autoavaliação dos conhecimentos adquiridos se revelaram muito positivos. Conclui-se que este caso poderá servir de reflexão e inspiração a outras bibliotecas que procurem potenciar boas práticas na escrita académica dos alunos universitários.

Palavras-chave: Literacia da Informação. Formação de Utilizadores. Plágio. Escrita Académica. Citações e referências. 


\section{To quote and refer: a formative strategy for the ethical use of information and plagiarism prevention in academia}

Starting from the hypothesis of having a greater impact in the prevention of plagiarism if a significant intervention is carried out along the academic formation of the students, in particular in information literacy, it is intended to observe how the specific training in citations and references contributes to prevent plagiarism. A case study is presented, focusing on the analysis of questionnaire surveys for higher education students. A training module is described - To quote and refer with the APA style considered strategic for the prevention of academic plagiarism, framed as a response to users' needs and supported in the teaching of competences in information literacy, as a strategy to prevent plagiarism. The library's training program, based on international standards for teaching information literacy, and devoted itself to instruction in research, selection, evaluation, use and presentation techniques, added a module whose evaluation and self-assessment results of acquired knowledge proved to be very positive. It is concluded that this case may serve as a reflection and inspiration for other libraries that seek to promote good practices in university student's academic writing.

Keywords: Information Literacy. User Education. Plagiarism. Academic Writing. Quotations and References.

Recebido em 12.07.2017 Aceito em 30.07.2019

\section{Introdução}

O debate em torno do plágio na academia tem acontecido um pouco por todo o mundo. Notícias de políticos em cujas teses foi detetado plágio são sinais de como a sociedade está atenta a estas práticas. Nas universidades, diversas estratégias têm sido tomadas para dirimir este fenómeno, sendo o uso de software antiplágio uma das mais conhecidas (KOKKINAKI; DEMOLIOU; IAKOVIDOU, 2015). As bibliotecas, por seu lado, assistem a diversas alterações sociais que se conjugam no que pode ser interpretado como o ambiente ideal para surgimento do plágio: mais recursos de informação, maior acesso a formatos digitais, mais e 
melhores meios de comunicação que resultam numa maior facilidade de obter informação em qualquer suporte, de a copiar e de a reutilizar. A questão principal não está nesta reutilização, que é desejável, mas na possibilidade de que seja feita sem cumprir pressupostos éticos e legais. De facto, o processo de copiar e colar é apenas uma etapa para o processamento da informação e a sua transformação em novo conhecimento (BOUKHELIFA; BRIAT; CARBILLET; MOURTADA; MULOT, 2013).

O contexto digital em que a informação emerge coloca agora renovadas questões relacionadas com o acesso à informação e sobretudo à forma como a integridade, confiabilidade e autoridade podem permanecer como suas propriedades intrínsecas, independentemente da reutilização que dela é feita. No caso do plágio, estas propriedades são corrompidas, comprometendo a própria informação. O objetivo do presente artigo é realizar uma reflexão sobre a matéria, apresentando uma análise de um módulo de formação ministrado por bibliotecários, no ensino superior em Portugal, através do ensino de métodos para realizar citações e referências bibliográficas, como profilaxia perante o plágio.

Em contexto universitário, o trabalho académico adquire maior complexidade e, desejavelmente, maior profundidade, através do desenvolvimento da reflexão e do sentido crítico. O exercício que se solicita aos estudantes é que desenvolvam uma escrita académica elaborada de forma cuidada e fundamentada. E que esta fundamentação, assente nos pressupostos do método científico, que requer a inclusão de citações e referências bibliográficas. A escrita académica convoca portanto múltiplos contributos: fontes, textos, autores, ideias, referências. A literacia de informação vem suprir a necessidade no treino de habilidades para lidar com informação e desenvolver competências que permitam usufruir e beneficiar dos recursos do conhecimento, porque incide precisamente na forma como se utiliza a informação para diversos fins.

\section{Revisão de Literatura}

O propósito da literacia da informação é o desenvolvimento de competências transversais que possam ser utilizadas ao longo do percurso de aprendizagem formal do estudante, mas igualmente ao longo da vida. No ensino superior, as competências em literacia de informação são um investimento imprescindível que os estudantes devem fazer, uma vez que ao valorizar a informação e a forma de a gerir, poderão colher as potencialidades que apresenta no exercício futuro de uma profissão capaz e competente e de uma cidadania ativa e interventiva.

No meio académico, quando o aluno sabe pesquisar, localizar, selecionar, sintetizar e apresentar informação de uma forma ética e legal (ALA, 1989), melhora a validade científica dos seus textos. Com este pressuposto podemos concluir que através da literacia de informação é possível melhorar significativamente a eficácia da escrita académica. Por outras palavras, o conhecimento prático e técnico em literacia de 
informação permite ao aluno dispor de ferramentas que auxiliam na produção do seu discurso, a apresentar em âmbito universitário (SANCHES, 2014, p. 22-23). A proficiência e domínio de determinado tema de investigação são tanto mais confirmados quanto o domínio dos vários saberes associados à literacia da informação se aprofundam: pesquisa de informação num catálogo, motor de busca ou a base de dados; uso de operadores booleanos; avaliação de fontes na sua validade e autoridade; realização de citações de forma apropriada e enquadrada num texto; compreensão do que é o plágio e como evitá-lo; organização de bibliografia, entre outras competências.

Já no início deste século a ALA (2001) se tinha referido a um parâmetro de competências relacionado com esta área, afirmando, por um lado, que o "aluno alfabetizado em informação entende muitas das questões éticas, legais e socioeconómicas que envolvem a informação e as tecnologias da informação". Por outro, que o "aluno alfabetizado em informação reconhece o uso de fontes de informação na comunicação de um produto ou desempenho."

Continua a perceber-se a importância de formar os estudantes para estas matérias nos padrões de competências emanados pela mesma associação, e recentemente atualizados na Framework for Information Literacy for Higher Education (ALA, 2016). Neste novo enquadramento são enfatizados nos estudantes o dinamismo, a flexibilidade, o crescimento individual e a aprendizagem em comunidade, estabelecendo-se para promover estas características, algumas linhas de rumo coerentes, mas flexíveis, organizadas em torno de seis conceitos chave para a compreensão e aplicação da literacia da informação: $A$ autoridade é construída e contextual; $A$ criação de informação como um processo; $A$ informação tem valor; $A$ pesquisa como investigação; $A$ comunidade académica como diálogo; Pesquisar como exploração estratégica.

Particularmente quando é referida a informação como valor, referem-se muitas das ideias que estão em causa no âmbito desta temática, esperando-se que o estudante alfabetizado em informação saiba (ALA, 2016, p.6):

- Dar crédito às ideias originais dos outros através de atribuição e citação apropriadas;

- Entender que a propriedade intelectual é uma construção jurídica e social que varia de acordo com a cultura;

- Articular o propósito e as características distintivas dos direitos autorais, o uso justo, o acesso aberto e o domínio público;

- Compreender como e por que alguns indivíduos ou grupos de indivíduos podem estar sub-representados ou ser sistematicamente marginalizados dentro dos sistemas que produzem e disseminam informações; 
- Reconhecer questões de acesso ou falta de acesso a fontes de informação;

- Decidir onde e como as suas informações são publicadas;

- Entender como a mercantilização das suas informações pessoais e interações on-line afeta as informações que recebem e as informações que produzem ou disseminam online;

- Fazer escolhas informadas sobre suas ações on-line em plena consciência sobre questões relacionadas com a privacidade e comodato de informações pessoais.

Este mesmo documento sublinha que os estudantes que estão a desenvolver as suas competências em informação devem (ALA, 2016, p.6):

- Respeitar as ideias originais dos outros;

- Valorizar as habilidades, o tempo e o esforço necessários para produzir conhecimento;

- Ver-se como contribuintes do mercado da informação em vez de apenas consumidores;

- Sentir-se inclinados a examinar seu próprio privilégio de informação.

As competências em literacia de informação apontam, mais amplamente, para um percurso composto genericamente pelas etapas: localizar, selecionar, avaliar, sintetizar e apresentar informação. E estas etapas têm sido objeto de formação nas bibliotecas universitárias, assentes nas necessidades detetadas e na reflexão teórica (LOPES; SANCHES; ANDRADE; ANTUNES; ARÉVALO, 2016).

Alguns autores (VELOSO; COSTA; LOPES, 2010, p. 102), já referiam que o desenvolvimento de sessões formativas de base transversal e abrangente podem contribuir para melhorar o sucesso académico dos estudantes, apontando como exemplos deste tipo de ação os métodos de estudo e gestão do tempo; a utilização de infraestruturas bibliográficas; a utilização do sistema institucional de informação e comunicação; as estratégias de pesquisa e gestão de conteúdos e bibliografias; e as regras de organização e apresentação de trabalhos científicos/académicos. A gestão de informação como uma habilidade a desenvolver nos estudantes deve ser, portanto, transversal à vida académica.

No que respeita especificamente ao ensino de competências no domínio da gestão de bibliografia e elaboração de citações e referências, elas são frequentemente abordadas em disciplinas de metodologia, no ensino superior. Porém, estas disciplinas são ministradas muitas vezes no primeiro ano do ensino superior, o que pode fazer com que nem sempre seja uma matéria amplamente compreendida e aplicada por estes estudantes. De facto, Allan (2010) sublinhava a importância de desenvolver competências em literacia da informação nos estudantes que 
desenvolvem investigação (portanto em segundo e terceiro ciclo de ensino superior), já que nestes as necessidades de lidar com informação se acentuam. E acrescentava que alguns estudantes iniciam 0 seu doutoramento utilizando uma gama muito básica de fontes de informação, por exemplo, livros didáticos e algumas revistas (impressas ou eletrónicas), conjugadas com a pesquisa simples na internet. Porém, rapidamente se dão conta de que para serem bem-sucedidos, precisam de desenvolver habilidades avançadas na pesquisa e gestão de informação. É nesta fase que os bibliotecários devem atuar (Allan, 2010, p. 97). Por isso se torna importante a oferta formativa nas matérias relativas às citações e referências ministrada por bibliotecários. Bodi (1998) já referia, a este propósito, que os bibliotecários são partes implicadas no uso ético da informação. A autora mencionava inclusivamente que o combate ao plágio deve partir de uma cultura ética, em que o respeito por si próprio e pelo outro devem imperar, tal como o estabelecimento e transmissão de princípios relativamente à propriedade, direito à privacidade, responsabilidade social, entre outros, podem ser uma forma mais significativa de alterar os comportamentos dos estudantes face a esta matéria (BODI, 1998, p. 462-463)

Citações e referências têm diversas funções. Lopes (2013, p. 2324), recorrendo a vários autores, realça a importância das citações para confirmação, perante o leitor, de diversas situações: que o texto foi lido, que a informação aí obtida foi incorporada na construção do nosso conhecimento e que existe um compromisso abrangente, nomeadamente face às matérias e face aos autores citados, sublinhando que as citações são imprescindíveis uma vez que as fontes citadas sustentam as tomadas de decisão, contribuem para diferenciar o importante e o acessório e elencam as principais tendências na área de estudo, permitindo a consolidação do conhecimento. Nesta mesma linha, outros autores (BURBULES, 2015; ALONSO-ARÉVALO, 2017) referem que a citação é uma forma de sustentar a opinião do autor, mas também uma demonstração das redes que são formadas entre investigadores, com base no reconhecimento e respeito, além de serem ainda uma forma importante de avaliação da produção científica, dentro de um sistema complexo que gera a bibliometria e os fatores de impacto.

O plágio ocorre sempre que os pressupostos que motivam a realização de citações e referências bibliográficas não são tomados em conta. Mas, se anteriormente se acreditava que o plágio ocorria devido a fatores individuais (traços de personalidade, atitudes morais ou estratégias de aprendizagem), atualmente a literatura mostra que existe uma influência acentuada do contexto (PABIAN, 2015). Isto significa que a prevalência de estudantes que cometem plágio no ensino superior é significativa porque o contexto o propicia (PUGA, 2014). Segundo Pabian (2015), no ensino superior perpetuam-se as formas de ensino estáticas e de reprodução, que são nutridas por estudantes, professores e políticas públicas. E sublinha que o conhecimento aí ministrado requer a memorização e replicação, as aulas são em si mesmas projeções do que 
está escrito, a comunidade académica partilha e reproduz os seus próprios discursos e os índices e rankings assentam em grande parte neste sistema de reprodução.

É também este o cenário do caso que aqui se expõe. Numa biblioteca de ensino superior, pertencente a uma grande universidade em Portugal, sentiu-se a necessidade de atuar na construção de estratégias que permitissem aos alunos lidar com a informação de modo informado e ético. Kokkinaki, Demoliou e Iakovidou (2015), num estudo transversal a diversas universidades cipriotas, recomendam como medidas importantes: formar os estudantes acerca do que é o plágio e sobre a forma de o evitar, implementar políticas e procedimentos preventivos e punitivos nas universidades e, ainda, adotar um software para deteção do plágio.

Puga (2014, p. 137) também menciona algumas recomendações para a situação, mas mais centradas na formação. Uma é pela consciencialização acerca de princípios éticos associados à produção de conhecimento, outra relativa à gestão do tempo, já que os estudantes apontam a estratégia de copiar e colar como aquela em que se obtêm mais resultados mais rapidamente $e$, finalmente, a de tornar os estudantes mais motivados para os conteúdos sobre os quais estão a realizar trabalhos, já que o plágio ocorre mais vezes quando há desinteresse sobre as matérias.

Tendo estas premissas em conta, mas também pela experiência acumulada na formação a estudantes dos vários ciclos de ensino, consideramos que uma forma importante para prevenir o plágio é fornecer ferramentas práticas para gerir a informação, nomeadamente ensinando as normas de citação e referenciação de bibliografia. Por este motivo foi implementado um módulo de formação com estes conteúdos. O objetivo deste estudo é pois apresentar os conteúdos do módulo e a forma como foi implementado e avaliado. Discutem-se os resultados e apontam-se para algumas recomendações, com base nesta experiência.

\section{Métodos}

Este artigo recorre a métodos qualitativos e quantitativos para descrever e explicar, como se implementou o módulo "Citar e Referenciar com a norma APA, 6th" e de que modo os utilizadores avaliaram as sessões ministradas. É importante referir que a biblioteca desenvolve formação sistematicamente desde o ano letivo de 2007/2008 (SANCHES; REVEZ; LOPES, 2015), tendo adaptado o mesmo às necessidades dos utilizadores, ao longo dos anos.

Os programas de formação da biblioteca baseiam-se em standards internacionais para o ensino da literacia da informação e por isso dedicam-se à instrução sobre técnicas de pesquisa, seleção, avaliação, utilização e apresentação da informação. Uma vez que o enfoque tem sido na primeira parte destas competências (pesquisar, selecionar e avaliar informação), houve necessidade de complementar a oferta formativa na segunda parte (utilizar e apresentar informação de forma ética e legal), 
nomeadamente acrescentando um módulo específico dedicado às citações e referências.

O estudo de caso foca-se nos anos letivos de 2015/2016 e de 2016/2017 e abrange todas as sessões deste módulo, que envolveu, no total, 128 alunos de duas instituições de ensino superior: a Faculdade de Psicologia e o Instituto de Educação, da Universidade de Lisboa, tendo sida obtida uma taxa de resposta de $100 \%$.

Os dados resultam de um inquérito por questionário presencial, distribuído aos indivíduos no final das sessões, que foi criado de acordo com dois objetivos: percecionar a avaliação do utilizador face à formação e percecionar a autoavaliação do utilizador relativamente às competências adquiridas.

De referir que no ano de 2015/2016 foi introduzido pela primeira vez este módulo, pelo que as primeiras sessões (dois workshops de formação livre) foram realizadas a título experimental. Posteriormente, já com os conteúdos consolidados, realizaram-se então, no ano letivo de 2016/2017, 4 sessões a pedido de docentes (com a ida do bibliotecário à sala de aula) e portanto integradas no conteúdo curricular de uma disciplina introdutória (10 ano de licenciatura) e 5 workshops de inscrição livre (frequentados por mestrados e doutorandos).

Realizaram-se assim um total de 11 sessões, distribuídas como se observa na tabela seguinte.

Figura 1. Sessões realizadas e estudantes envolvidos

\begin{tabular}{llrr}
\hline Sessões & \multicolumn{1}{c}{ Tipo } & $\begin{array}{c}\text { Estudantes } \\
\text { Envolvidos }\end{array}$ & $\begin{array}{c}\text { Número de } \\
\text { Horas }\end{array}$ \\
\hline 1 Fev. 2016 & workshop & 9 & 2 \\
2 Abr. 2016 & workshop & 10 & 2 \\
3 Out. 2016 & sala aula & 9 & 2 \\
4 Out. 2016 & sala aula & 17 & 2 \\
5 Out. 2016 & sala aula & 22 & 2 \\
6 Nov. 2017 & sala aula & 11 & 2 \\
7 Fev. 2017 & workshop & 12 & 2 \\
8 Fev. 2017 & workshop & 12 & 2 \\
9 Mar. 2017 & workshop & 10 & 2 \\
10 Mar. 2017 & workshop & 9 & 2 \\
11 Abr. 2017 & workshop & 7 & 2 \\
\hline & & & \\
Totais & & 128 &
\end{tabular}

Fonte: produção da autora

Relativamente à avaliação, como referido, foi distribuído um inquérito por questionário, no final de todas as sessões realizadas. 
No questionário foram considerados dez itens para avaliação da formação e outros dez para autoavaliação, relativos às suas capacidades auto percebidas após a formação.

O grau de satisfação foi medido numa escala de um a quatro, sendo «um» o menos satisfeito e «quatro» o mais satisfeito.

\section{Figura 2. Inquérito ao Workshop Citar e Referenciar}

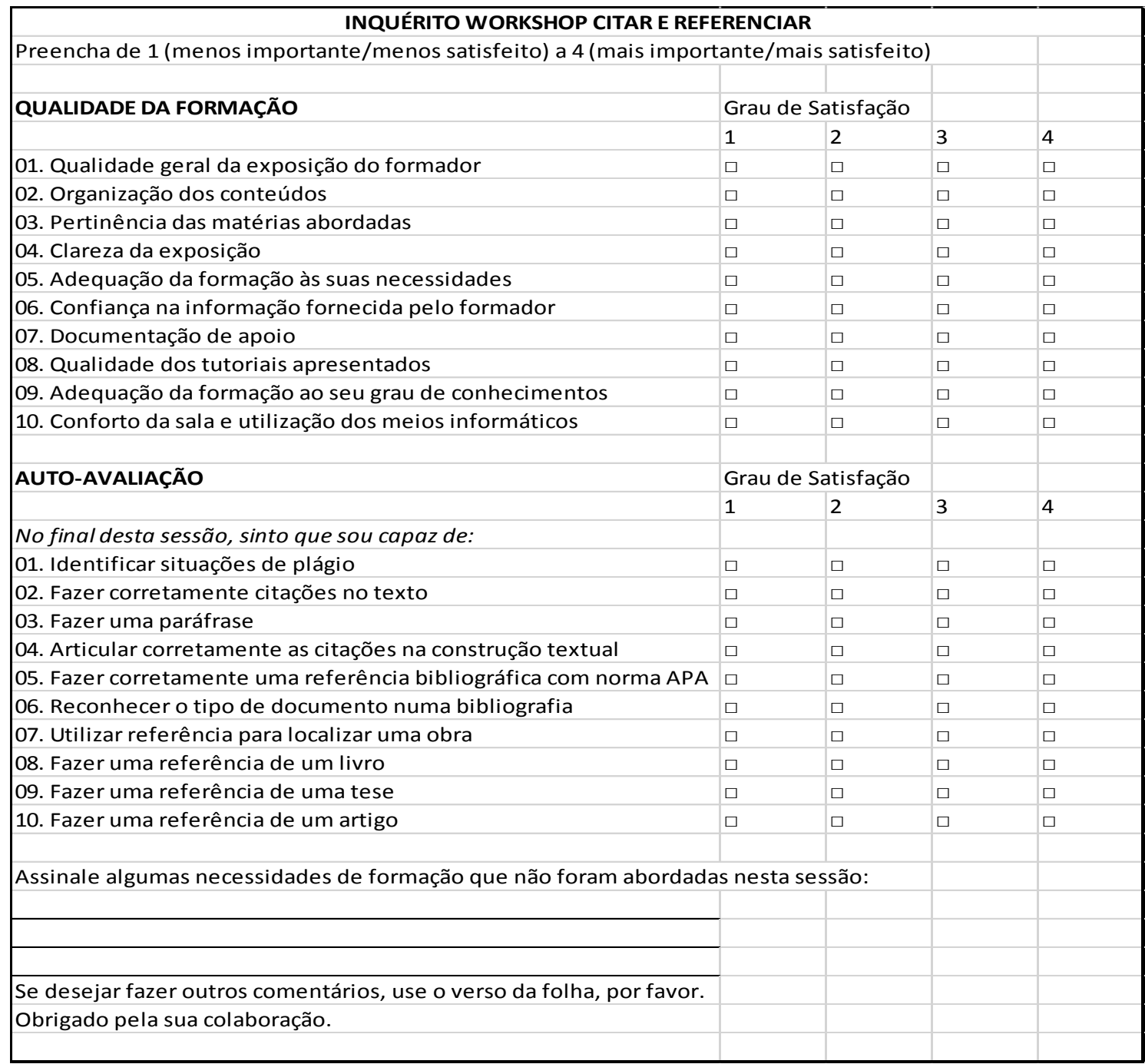

Fonte: produção da autora

As questões foram quantificadas e analisadas de modo a obter-se um panorama geral da avaliação do módulo, quer relativamente às sessões ocorridas em sala de aula, quer aos workshops de inscrição livre.

\section{Resultados}

A inclusão deste tópico na oferta formativa da biblioteca apresentouse como resposta às necessidades dos utilizadores, mas também à reflexão lançada no início desta comunicação. Torna-se relevante consolidar as aprendizagens de perícias técnicas na gestão de bibliografia, 
pois estas vão fortalecer as competências académicas que o estudante precisa.

Enquadrando-as como parte da escrita académica, nomeadamente ao relacionar e exemplificar através das teses e dissertações em desenvolvimento pelos próprios alunos, fica assegurado o interesse nas matérias. Por outro lado, é importante mostrar ao aluno que é a sua autoridade na escrita do texto académico (o ser autor, sendo original no ponto de vista que coloca sobre as ideias de outros) que alimenta a produção textual e é esse aspeto que é valorizado, não a reprodução de ideias por si só. O estudante deixa de ser reprodutor de conteúdos, para tomar consciência da sua capacidade criativa, a partir dos textos de outros, apoiado que está em estratégias para a aprendizagem individual e autónoma.

Os conteúdos do módulo, de duas horas, centraram-se nas seguintes matérias:

- Porquê citar e fazer referências?;

- Uso ético da informação;

- Recolha dos dados para citar;

- Apresentar as citações no texto;

- Citações \& paráfrases;

- Construção textual;

- Fazer referências bibliográficas com a norma APA (livros, capítulos de livros, teses, artigos impressos e eletrónicos, outros casos).

$\mathrm{Na}$ abordagem habitual, a sessão começava por expor a ideia de que os autores que visitamos (nas nossas leituras) e que apreciamos serão nossos convidados nos trabalhos escritos que faremos. Damos a conhecer estes autores a outras pessoas, possibilitamos a quem lê a consulta direta às fontes e o aprofundamento das ideias aí obtidas, atribuímos o mérito a quem é devido, garantimos credibilidade às nossas ideias ao possibilitar a confirmação da veracidade das mesmas, e cumprimos as normas da cientificidade académica, ao mesmo tempo que evitamos o plágio. Sublinhava-se ainda que, na elaboração de um texto académico, o trabalho de pesquisa deve ser baseado em fontes fidedignas, que sustentarão as ideias apresentadas. Neste contexto, é recorrente a utilização de palavras, expressões, excertos ou ideias consultadas nas diversas fontes. $O$ facto de não se fazer referência a essas mesmas fontes, quer no texto, através da citação, quer no final do texto, com a devida referência bibliográfica, denuncia a prática de plágio. As estratégias para, de modo muito concreto, evitar o plágio, passam por saber citar e referenciar corretamente. Além das estratégias de recuperação de informação ou sobre a forma de a organizar, tópicos que são igualmente desenvolvidos durante a formação, um aspeto significativo corresponde a estratégias de escrita onde se inclui a citação em diversos 
formatos (direta, curta ou longa, e indireta), ponto em que se fornecem algumas ideias práticas para lidar com a obrigatoriedade de escrever e com a gestão do tempo.

Apresentam-se seguidamente os resultados dos inquéritos distribuídos no final destas sessões, já previamente tratados e parcialmente analisados internamente (Lopes, 2017). A análise dos dados referentes a cada um dos conjuntos de questões deste módulo de formação - o primeiro conjunto relativo à qualidade da formação e o segundo relativo à autoavaliação - apresenta-se em separado, nas tabelas seguintes.

Figura 3. Conjunto de questões relativas à qualidade da formação

\begin{tabular}{llc}
\hline Questões & Qualidade da formação & Satisfação \\
\hline Q1 & Qualidade geral da exposição do formador & $\mathbf{9 7 \%}$ \\
Q2 & Organização dos conteúdos & $\mathbf{1 0 0 \%}$ \\
Q3 & Pertinência das matérias abordadas & $\mathbf{1 0 0 \%}$ \\
Q4 & Clareza da exposição & $\mathbf{1 0 0 \%}$ \\
Q5 & Adequação da formação às suas necessidades & $\mathbf{9 7 \%}$ \\
Q6 & Confiança na informação fornecida pelo formador & $\mathbf{9 7 \%}$ \\
Q7 & Documentação de apoio & $\mathbf{9 9 \%}$ \\
Q8 & Qualidade dos tutoriais apresentados & $\mathbf{1 0 0 \%}$ \\
Q9 & Adequação da formação ao seu grau de conhecimentos & $\mathbf{9 5 \%}$ \\
Q10 & Conforto da sala & $\mathbf{9 6 \%}$ \\
\hline & & $\mathbf{9 8 \%}$
\end{tabular}

Fonte: produção da autora

Figura 4. Conjunto de questões relativas à auto-avaliação

\begin{tabular}{llc}
\hline Questões Auto-avaliação & Satisfação \\
\hline Q1 & Identificar situações de plágio & $\mathbf{8 8 \%}$ \\
Q2 & Fazer corretamente citações no texto & $\mathbf{8 7 \%}$ \\
Q3 & Fazer uma paráfrase & $\mathbf{9 6 \%}$ \\
Q4 & Articular corretamente as citações na construção textual & $\mathbf{9 5 \%}$ \\
Q5 & Fazer corretamente uma referência bibliográfica com norma APA & $\mathbf{8 7 \%}$ \\
Q6 & Reconhecer o tipo de documento numa bibliografia & $\mathbf{9 1 \%}$ \\
Q7 & Utilizar referência para localizar uma obra & $\mathbf{9 6 \%}$ \\
Q8 & Fazer uma referência de um livro & $\mathbf{9 5 \%}$ \\
Q9 & Fazer uma referência de uma tese & $\mathbf{9 1 \%}$ \\
Q10 & Fazer uma referência de um artigo & $\mathbf{9 0 \%}$ \\
\hline & & $\mathbf{9 2 \%}$
\end{tabular}

Fonte: produção da autora 


\section{Discussão e conclusões}

Os resultados apresentados mostram que o primeiro impacto deste módulo de formação é muito positivo. Se por um lado a formação foi ministrada a alunos do $1^{\circ}$ ano, pela primeira vez, a pedido dos docentes, por outro foi possível consolidá-la com a oferta em modalidade de workshops de inscrição livre, frequentada por alunos de 20 e $3^{\circ}$ ciclo. A constatação da importância das matérias aqui abordadas, por parte dos alunos, é visível nos níveis de satisfação encontrados, numa média de $\mathbf{9 8 \%}$, reforçando a importância do papel da biblioteca no apoio ao percurso académico dos alunos. Por outro lado, a média de $\mathbf{9 2} \%$ da qualidade obtida na autoavaliação é um indicador sólido de que a importância desta formação também é percecionada, de forma geral, pelos alunos, que conseguiram integrar estes conhecimentos no quadro das suas aprendizagens.

A organização de conteúdos relativos às citações e referências, associada aos conteúdos curriculares, bem como a explicação de que o que é valorizado em âmbito universitário passa mais pelo pensamento crítico e pela interpretação pessoal, assente nas ideias de outros, foram fatores decisivos para estes resultados. Lynch (2010), aludindo ao processo artístico como criação, referia que temos de reconsiderar a forma como a arte é produzida, sublinhando que a não originalidade tem de ser esperada e aceite. Nas suas palavras, não é que a fraude e o plágio tenham de ser aceites (embora até possam ser), mas antes que as derivas ou os re-arranjos do trabalho possam ser aceites como meios válidos de expressão. Isto significa que a tónica deve ser colocada não na criação ou replicação, mas na comunicação (LYNCH, 2010, p. 123). Isto é, na voz autoral, a forma como cada um interpreta a informação e a reenvia para o mundo.

No caso em apreço procurámos apresentar evidências de uma formação que teve por objetivo a lecionação de estratégias com vista a evitar o plágio, particularmente ensinando as formas de corretamente citar e referenciar. Os resultados da avaliação da formação, bem como da auto-avaliação face aos conhecimentos adquiridos, deixam-nos esperançados face à diminuição do plágio, precisamente pela compreensão, por parte dos alunos, de que este não beneficia os resultados avaliáveis dos trabalhos académicos.

Considerou-se estratégica a inclusão de uma nova área - Citar e referenciar com a norma $A P A$ - para a prevenção do plágio académico, para além do programa base que a biblioteca tem vindo a desenvolver (que já incluía o apoio a trabalhos académicos com pesquisa avançada, gestores de referências bibliográficas, e o apoio à gestão da informação para teses e dissertações). Os resultados alcançados mostram que o conhecimento destas matérias é útil e produziu impacto nos estudantes.

A sequência destas ações, espera-se, é a diminuição do plágio na produção científica e académica destes alunos que, mais conscientes da forma como se escreve, adquiriram ferramentas práticas para o evitar. 
Conclui-se que este caso poderá servir de reflexão e inspiração a outras bibliotecas que procurem potenciar melhorias na escrita académica dos alunos universitários.

\section{Referências}

AMERICAN LIBRARY ASSOCIATION (ALA). Presidential Committee on Information Literacy: final report. [s.I.]: ALA. 1989. Disponível em: http://www.ala.org/acrl/publications/whitepapers/presidential. Acesso em: 12 jul. 2017.

AMERICAN LIBRARY ASSOCIATION (ALA). Objectives for information literacy instruction: a model statement for academic librarians. ACRL. 2001. Disponível em:

http://www.ala.org/acrl/standards/objectivesinformation. Acesso em: 12 jul.2017.

AMERICAN LIBRARY ASSOCIATION (ALA). Framework for information literacy for higher education. Chicago, IL: ACRL, 2015. Disponível em: http://www.ala.org/acrl/standards/ilframework. Acesso em : 12 jul.2017.

ALLAN, B. Supporting research students. London: Facet Publishing, 2010.

ALONSO-ARÉVALO, J. Los gestores de referencias en el trabajo de bibliotecario y documentalista. Desiderata, v. 2, n. 4, p. 38-42, 2017.

BODI, S. Ethics and information technology: Some principles to guide students. The Journal of Academic Librarianship, v. 24, n.6, p. 459-463, 1998.

BOUKHELIFA, N., BRIAT, V., CARBILlET, M., MOURTADA, A., MULOT, H. Copier-coller, ça s'apprend!. Cahiers Pedagogiques, v. 68, n. 508, p. 44$45,2013$.

BURBULES, N. C. The changing functions of citation: from knowledge networking to academic cash-value. Paedagogica Historica, v. 51, n.6, p. 716-726, 2015.

KOKKINAKI, A. I., DEMOLIOU, C., \& IAKOVIDOU, M. Students' perceptions of plagiarism and relevant policies in Cyprus. International Journal for Educational Integrity, v.11, n.1, p. 1-11, 2015.

LOPES, Carlos. Como fazer citações e referências para apresentação de trabalhos científicos: aplicação prática da norma APA. 6.ed. Lisboa: ISPA, 2013.

LOPES, Carlos., SANCHES, T., ANDRADE, I., ANTUNES, M. D. L., ALONSOARÉVALO, J. Literacia da informação em contexto universitário. Lisboa: ISPA, 2016.

LOPES, Cristina. Relatório - formação 2016 (não publicado). Lisboa: Instituto de Educação e Faculdade de Psicologia, Universidade de Lisboa, (2017, Janeiro). 
LYNCH, C. CTRL+C, CTRL+V: The Rise of the copy and the fall of the author. In: CLAPP, E.P. (ed.). 20under40: Re-inventing the Arts and Arts Education for the 21st Century. Bloomington: AuthorHouse, 2010. P.112125.

PABIAN, P. Why 'cheating' research is wrong: new departures for the study of student copying in higher education. Higher Education, v. 69, n.5, p. 809-821, 2015.

PUGA, J. L. Analyzing and reducing plagiarism at university. European Journal of Education and Psychology, v. 7, n. 2, p. 131-140, 2014.

SANCHES, T. (2014). Interseções da pedagogia universitária com a biblioteca: da pesquisa de informação à escrita académica. Revista Portuguesa de Pedagogia, v. 48, n.2, p. 9-15. Disponível em: http://dx.doi.org/10.14195/1647-8614 48-2 1. Acesso em: 12 jul.2017. SANCHES, T., REVEZ, J., LOPES, C. Sete anos de experiência, sete lições para o futuro: formando utilizadores em literacia de informação. CONGRESSO NACIONAL DE BIBLIOTECÁRIOS, ARQUIVISTAS E DOCUMENTALISTAS, APBAD, 12, 2015. Anais... Disponível em: http://www.bad.pt/publicacoes/index.php/congressosbad/article/view/131 2. Acesso em: 12 jul. 2017.

VELOSO, H., COSTA, A. F. \& LOPES, J. T. Factores, representações e práticas institucionais de promoção do sucesso escolar no ensino superior. Porto: Universidade do Porto, 2010. 